\title{
Brief Communication: On the rapid and efficient monitoring results dissemination in landslide emergency scenarios: the Mont de La Saxe case study
}

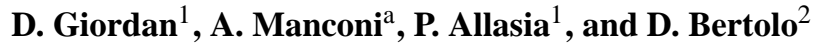 \\ ${ }^{1}$ Geohazard Monitoring Group, CNR IRPI, Strada delle Cacce 73, 10135 Turin, Italy \\ ${ }^{2}$ Struttura Attività Geologiche Regione Autonoma Valle d'Aosta, Rue Région d'Amérique 33, 11020 Aosta, Italy \\ a now at: Swiss Federal Institute of Technology, Department of Earth Sciences, Zurich, Switzerland
}

Correspondence to: D. Giordan (daniele.giordan@irpi.cnr.it)

Received: 17 March 2015 - Published in Nat. Hazards Earth Syst. Sci. Discuss.: 21 April 2015

Revised: 25 August 2015 - Accepted: 26 August 2015 - Published: 10 September 2015

\begin{abstract}
Straightforward communication of monitoring results is of major importance in emergency scenarios relevant to large slope instabilities. Here we describe the communication strategy developed for the Mont de La Saxe rockslide threatening La Palud and Entrèves hamlets in the Courmayeur municipality (Aosta Valley, Italy). Starting from the definition of actions and needs of the landslide management team, including scientists, technicians, civil protection operators, decision makers, and politicians, we show that sharing and disseminating ad hoc information simplifies the understanding of the landslide evolution, as well as the correct communication of the level of criticality.
\end{abstract}

\section{Introduction}

Large slope instabilities (LSI) include a wide range of landslide phenomena, from slow slope deformations to rapid and catastrophic rockslides. LSI geometry, as well as failure mechanisms, are deeply influenced by the background geological and hydrogeological conditions. One of the most critical issues related to LSI is their potential to evolve into high-velocity gravitational events, involving a partial or total portion of the unstable mass (e.g., rock falls and/or rock avalanches). In this context, the identification of surface displacements and/or deep-seated deformation often represents the key information for a proper understanding and interpretation of the phenomenon (Wieczorek and Snyder, 2009).
In the last 2 decades, monitoring systems ranging from in situ to remote sensing techniques have allowed retrieval of information on LSI deformation at unprecedented spatial and temporal resolution. Displacement monitoring is probably one of the most common approaches used to increase the background knowledge of an unstable slope (Balis et al., 2011). When a high hazard potential is recognized, intensive monitoring is preferred, allowing for the recognition of displacement trends, and eventually for the identification of precursors of a partial or complete landslide failure. Thus, intensive monitoring helps to protect inhabited centers and infrastructures surrounding the unstable mass (Xu et al., 2011). Monitoring networks of this kind consist of precise and automated instruments that can achieve accurate measurements of surface displacements at very high sampling rates, e.g., in near-real time (minutes to hours) or even in real time (Intrieri et al., 2012; Di Biagio and Kjekstad, 2007). These are the base elements for the application of Early Warning Systems (EWS) (Manconi and Giordan, 2014, 2015; Michoud et al., 2013). In this scenario, EWS relevant to displacement monitoring usually consist of three levels of attention (Intrieri et al., 2013): (i) an ordinary level, when displacements are below predefined thresholds, (ii) a pre-alarm level, used when the landslide shows displacements above the seasonal oscillation, and (iii) an alarm level, which identifies a critical activation of the unstable area. The application of complex monitoring networks to large landslides is documented in several reference papers (Brückl et al., 2013; Giordan et al., 2013; Lu et al., 2014; Malet et al., 2002; Tarchi et al., 
2003). However, strategies for the use and dissemination of such monitoring results, especially in emergency scenarios, are yet lacking in standards and best practices.

In this work, we describe a real case study, the Mont de la Saxe rockslide, a large and complex instability located in Val d'Aosta, northern Italy. We focus the attention on the characteristics of the monitoring procedures, as well as on the communication strategy developed to comply with the actions and needs of the different stakeholders involved.

\subsection{Mont da La Saxe rockslide: a complex LSI emergency scenario}

The Mont de La Saxe rockslide (hereinafter La Saxe) is a large instable slope located in the Aosta Valley region, northern Italy (Fig. 1). La Saxe rockslide is located in metasedimentary sequences cropping out along the left hand flank of the valley. These rocks belong to Ultra-Helvetic basal decollèment units located south of the Mt. Blanc crystalline massif and are made of very low-grade, intensely deformed Middle Jurassic meta-sedimentary sequences, including limestones and marls, argillaceous schists, black schists, micaschists, and calcschist with quartz-arenite layers (Perello et al., 1999; Leloup et al., 2005). In the area affected by the rockslide, the dominant black argillaceous schists prevalently dip to the SE, into the slope, with dip angles ranging between 20 and $60^{\circ}$ due to the effect of tectonic deformation events (Crosta et al., 2014, 2015). The La Saxe instability has an estimated total volume of more than $8 \times 10^{6} \mathrm{~m}^{3}$. The landslide extends between 1400 and $1870 \mathrm{~m}$ a.s.l., over an area of about $150000 \mathrm{~m}^{2}$, with maximum horizontal length of about $550 \mathrm{~m}$, maximum width of about $420 \mathrm{~m}$, and average slope gradient of $37^{\circ}$. The upper scarp is about $200 \mathrm{~m}$ wide and it is characterized by a steep rock wall some tens of meters high, locally oriented along sub-vertical schistosity planes (Crosta et al., 2014).

An automatized near-real time monitoring network (see details in Fig. 1) was installed and developed in 2009, when the high level of criticality of the La Saxe rockslide for La Palud and Entrèves hamlets was officially recognized. The monitoring network permitted detection and monitoring of the evolution of several landslide sectors characterized by different kinematic behaviors. Starting from 2014, the Mont de La Saxe landslide was classified as national emergency, and the local authorities are supported by the Italian National Civil Protection Department. Thus, a specific Landslide Management Team (LMT) has been created to cope with the emergency activities.

Starting from the management system of the monitoring network, we defined a specific communication strategy aimed at supporting the decision makers during the critical phases of the landslide evolution, and to share the information with all the stakeholders. The main goals of our communication strategy are: (i) update all LMT members in nearreal-time with essential information; (ii) deliver specific peri- odic (or on-demand) reports for each LMT role, summarizing the evolution of the LSI in a defined time period; (iii) fully exploit the potential of the data available, and provide the correct information on the landslide evolution to all people involved in the emergency scenario. In the following, we describe the details of the strategy, as well as how we applied it to the management of the La Saxe emergency.

\subsection{La Saxe landslide management team}

The management of a complex network to monitor LSI evolution is a difficult task, chiefly during emergency conditions. Usually, a specific working group of people (i.e., LMT) is set up with the aim of understanding the landslide evolution, to plan civil protection activities, as well as to organize initial remedial activities. LMT members have to accomplish different actions, depending on their specific role and the phases associated with the evolution of the landslide. In the La Saxe case study, the team is composed of multiple stakeholders, including scientists, civil protection authorities, and technicians. By considering the different background knowledge, needs, and duties of the LMT members, we identified three different categories:

i. ROLE-1, composed of authorities such as the mayor, aldermen and other politicians that often do not have a specific technical background on landslide hazards. These people are usually the terminal of a decision chain, and have the responsibility to eventually activate measures reducing direct risks to people and/or infrastructures. According to the limited technical knowledge of people composing the ROLE-1, their principal need is to clearly understand the criticality level of the current situation by providing access to clear and meaningful information before making decisions concerning public safety (Garcia and Fearnley, 2012).

ii. ROLE-2, composed of engineers, geologists, and others technicians that have a specific background knowledge and experience of landslides. Their tasks are mainly related to the exhaustive technical analysis of the landslide to support ROLE-1 in their decisions. This may include the analysis and comparison of different data sources such as surface deformation, deep-seated displacements, rain/snow precipitation data, groundwater variations, etc. In addition, ROLE-2 is usually responsible for the design of mitigation and/or protection measures. For this reason, they need to fully access the monitoring results in order to clearly understand the recent landslide evolution, as well as to plan their activities accordingly.

iii. ROLE-3, mainly composed of engineers and geologists, which have expertise on landslides monitoring and on EWS. Their tasks are aimed to develop and efficiently run the monitoring network, analyze and val- 


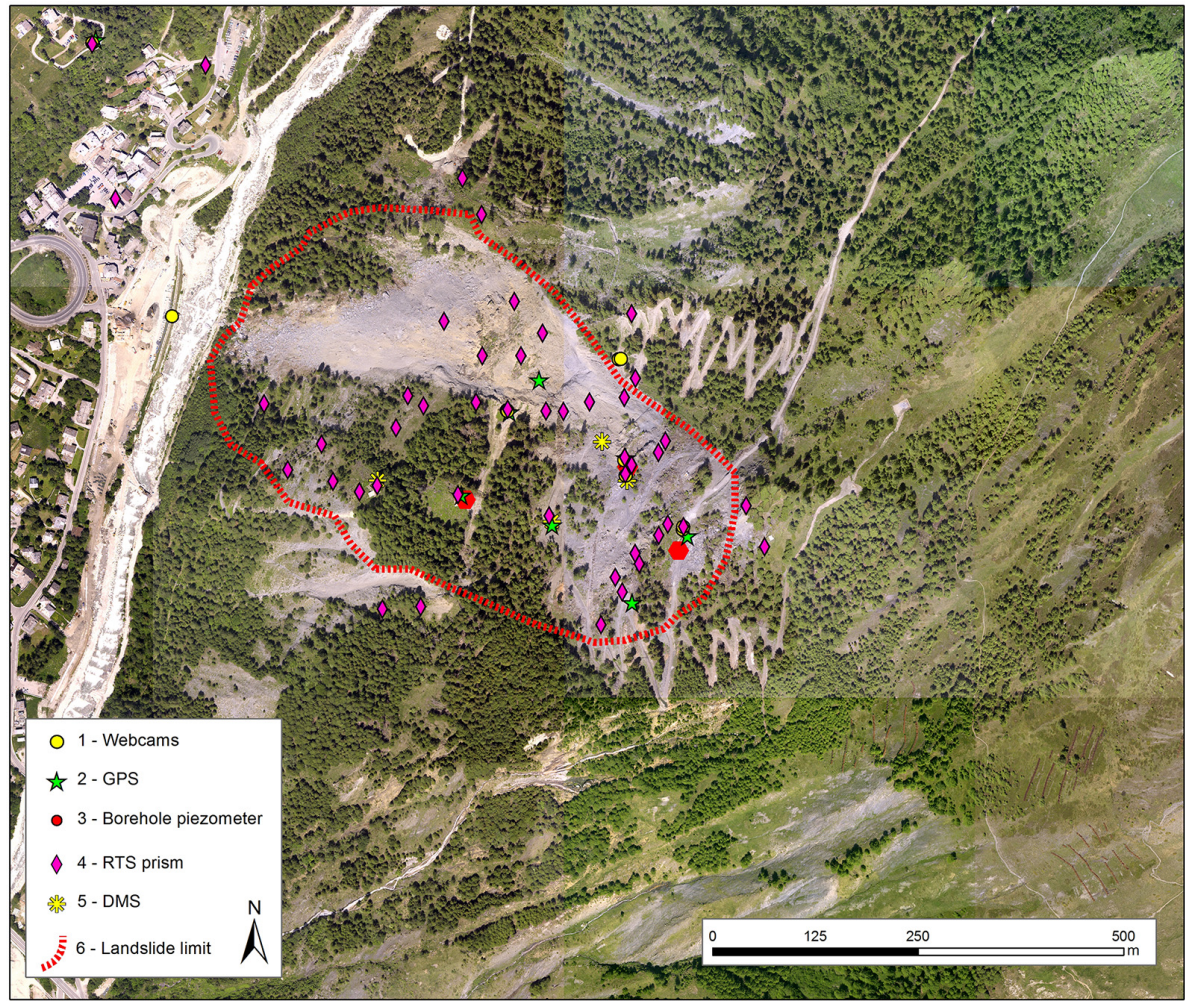

Figure 1. La Saxe intensive monitoring network composed of: (1) webcams; (2) GPS devices; (3) borehole piezometers; (4) Robotic Total Station network (surveying 36 optical targets), (5) DMS ${ }^{\mathrm{TM}}$ columns (Lovisolo et al., 2003; Blikra et al., 2013) and (6) limit of the unstable area.

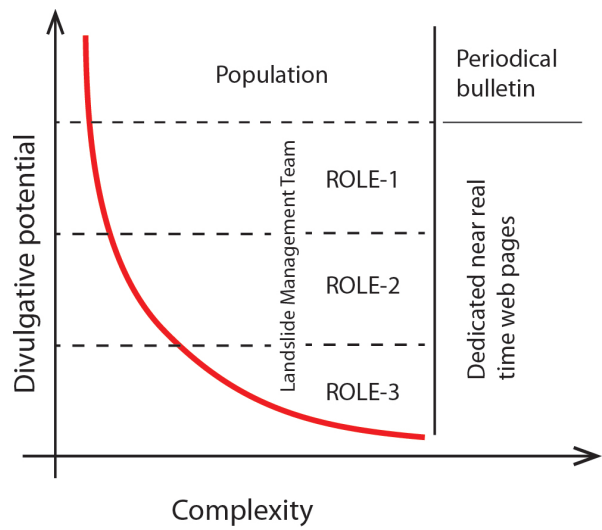

Figure 2. Communication strategy of monitoring results. The graph depicts how the potential of divulgation decays when the complexity of the graphical elaborates increases and also indicates the available products for the different stakeholders.

idate the data and the results, therefore supporting the other members of the LMT.

A common issue in standard approaches of data sharing is related to representation of the monitoring results. In particular, plots versus time might be difficult to read and understand for people not data familiar to deal with this kind of graph- ical. According to our experience, the presence of different monitoring points without a map that can represent the displacement of different landslide's sectors can limit the comprehension of the plot and correct understanding of the real situation. In complex emergency conditions, incorrect reading of monitoring results can lead to misunderstandings and unnecessary concerns (Mileti and Sorensen, 1990). Figure 2 shows how the potential of dissemination decays depending on the complexity of the representations used. For this reason, the graphic representation of monitoring results should be compatible with the background of the LMT recipients. Low levels of complexity of the representations helps population and ROLE- 1 to better understand the current status of the landslide phenomenon according to their specific interest. On the contrary, ROLE- 2 and ROLE-3 require more complex and detailed representations, to better evaluate the recent landslide evolution and its possible effects on the hypothesized scenarios.

Table 1 presents a schematic diagram summarizing the duties, actions and needs of LMT members acting in the La Saxe emergency scenario. In general, the results obtained via the monitoring network of La Saxe landslide are analyzed and shared by generating specific products considering two main temporal ranges: (i) near-real-time (described 
in Sect. 3.1) and (ii) periodical and/or on-demand basis (Sect. 3.2).

The LMT concept developed for Mont de La Saxe can be considered a general schematic representation. In each specific context, there might be some changes, and thus duties, needs and actions of the different LMT members which might have some overlaps. However, after the definition of LMT components, it is possible to focus on one of the most important points for the management of an emergency related to a natural hazard, i.e., the straightforward access to the available information, the data sharing, and the efficient communication of the actual status of the phenomenon.

\subsection{Near-real time presentation of monitoring results}

The dissemination of the monitoring results to La Saxe LMT members is based on the use of the ADVICE algorithm (Allasia et al., 2013). This procedure has been developed to perform a set of actions in near-real time (less than $30 \mathrm{~min}$ ), including the following: (i) data acquisition and transfer protocols; (ii) data collection, filtering, and validation; (iii) data analysis and restitution through a set of dedicated software; (iv) recognition of displacement/velocity threshold, early warning messages via SMS and/or emails; (v) automatic publication of the results on a dedicated web page. One of the main advances of the ADVICE method is that all the operations can be performed without installing dedicated software for the processing, exploitation, and management of the monitoring results. The access to the web page relevant to the monitoring results of La Saxe has been structured with multiple levels, corresponding to the three different LMT roles. Thus, the information is presented according to the specific background knowledge of each user. For example, ROLE-1 members have access only to the Synthesis page. This frontend view has been developed as a cockpit to supply the most relevant information, and to provide a rapid and straightforward overview on the actual landslide status. The Synthesis page contains the following: (i) the main meteorological parameters; (ii) the RTS displacement maps and plots with the indication of predefined threshold levels; (iii) the last images acquired by the webcams. In this page, people not familiar with time series plots may benefit from interpolated maps of the three-dimensional displacements produced in near-real time, which facilitate the understanding of the recent development of the phenomenon (Manconi et al., 2013a). On the other hand, ROLE- 2 members have access to additional information derived from the monitoring network. The monitoring data available (meteorological parameters, RTS, GPS, GB-SAR, and piezometers) are organized in a set of different representations, which mainly depend on the time window considered (e.g., monthly or weekly time series plots/displacement maps). Examples of different products that could be created starting from the same data set are presented in Figs. 3 and 4 and in Table 2. By considering the RTS data set, the system is able to publish a 3-D view of the slide with a contour map of the displacement dedicated to ROLE-1 (Fig. 3), a plot of the RTS targets' displacement for ROLE-2 (Fig. 4) and a table with the numerical value of target's velocity and displacement dedicated to ROLE-3 in Table 2 .

Among the available representations, Fig. 5 shows another example of the maps produced by in near-real time the system that comes from the integration of data retrieved via different monitoring instruments. Displacement rates measured by RTS and GB-SAR are interpolated in a unique representation generated via the ${ }^{\circ}$ 3DA approach (Manconi et al., 2013a). ROLE-2 members have access to interactive website features, such as a dynamic time series plot. This tool is extremely important, mainly because it allows direct exploration of the available data set, and comparison of different data sources. ROLE-3 develops and controls all the data processing from the measurement to the publication. For this reason, they need tools to check the system status and to identify eventual malfunctioning of the monitoring network and/or of the ADVICE system. In the case of the La Saxe case study, specific messages are issued (via SMS and e-mail) when the data on the web page is not up-to-date, indicating at which step the procedure encountered a problem. This allows for prompt action to restore the system.

ROLE-2 and ROLE-3 members also benefit from early warning messages produced by the ADVICE system when predefined thresholds on surface displacements are overcome. Messages are sent via SMS and/or e-mail immediately after the processing and publication online of the results relevant to the last measurement cycle. All the information provided via ADVICE, as well as additional data retrieved from other sources, joined with the in-depth knowledge of the landslide process, allows ROLE-2 and ROLE-3 members to evaluate and validate a potential situation of direct risk for the population and/or the infrastructures, and eventually transmit this information to ROLE-1 members.

The presented system has been used in particular during the two most critical activations of the slide (for further details please see Manconi and Giordan, 2014, 2015), when a temporary evacuation of the most dangerous area was decided by the authorities. In 2013, more than 100 people were evacuated from their houses from 5 May to 24 June, and, in 2014, more than 80 people did the same from 4 April up to 5 May. In these periods, the ADVICE was used by the Aosta Valley Geological Service to have a strict control of the most unstable area evolution and to support the decision of the Civil Protection. In this contest, the system was able to send alert messages (SMS and email) when the RTS prisms exceeded the predefined thresholds and to allow a web navigation from smartphones and other mobile devices. During the evacuation, the municipality organized several public assemblies to explain to the population the evolution of the slide and during these meeting the 3DA displacement maps were used to show the latest monitoring results to the population. 


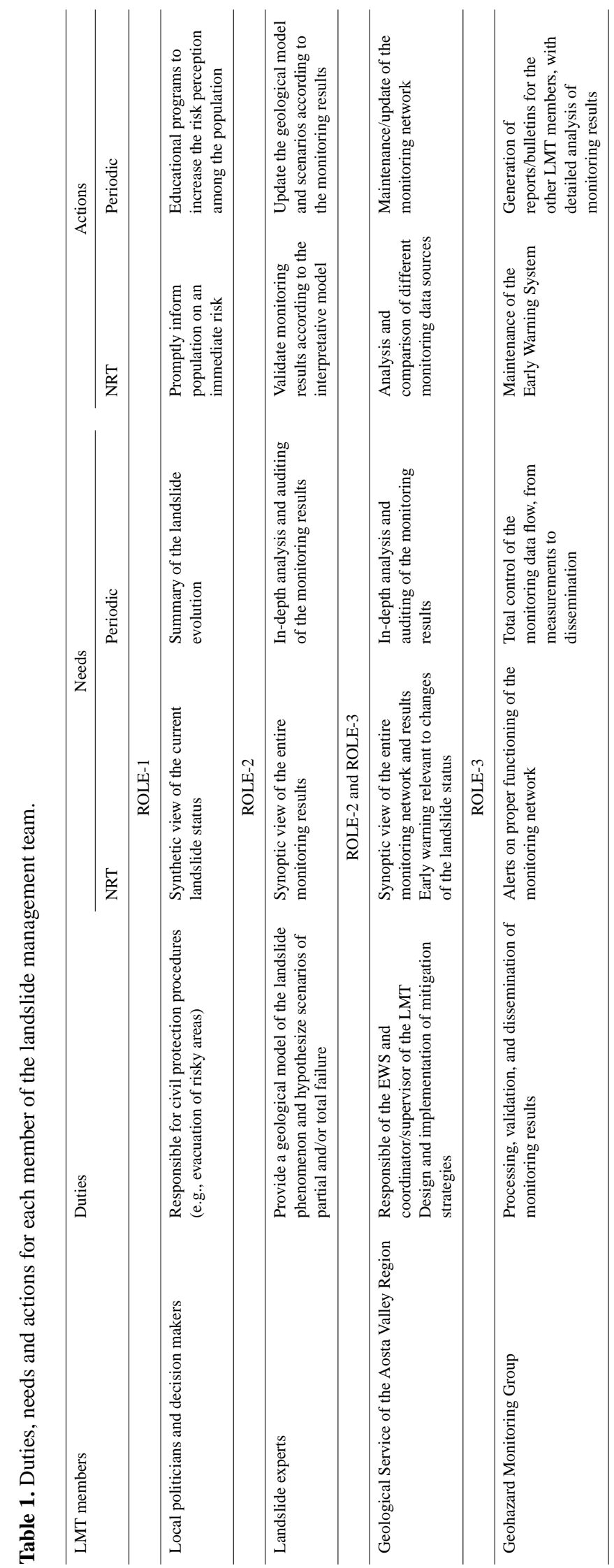


Table 2. Abstract of the numerical data published in near-real time on the website related to a $24 \mathrm{~h}$ period between $15-16 \mathrm{March} 2015$. This table is delivered in particular for ROLE-3. The following is presented in the table: displacements over the three coordinates $(x, y, z)$, line of sight displacement, planimetric and 3-D displacement resultants, amplitude and time when maximum velocities occurred in the reference period (both in line of sight and 3-D) and status with respect to the defined thresholds.

\begin{tabular}{|c|c|c|c|c|c|c|c|c|c|c|c|}
\hline Target & $\begin{array}{r}x \\
(\mathrm{~m})\end{array}$ & $\begin{array}{r}y \\
(\mathrm{~m})\end{array}$ & $\begin{array}{r}z \\
(\mathrm{~m})\end{array}$ & $\begin{array}{r}\text { LOS } \\
(\mathrm{m})\end{array}$ & $\begin{array}{l}x y \\
(\mathrm{~m})\end{array}$ & $\begin{array}{l}x y z \\
(\mathrm{~m})\end{array}$ & $\begin{array}{c}\text { MaxVLOS } \\
\left(\mathrm{mm} \mathrm{h}^{-1}\right)\end{array}$ & $\begin{array}{l}\operatorname{MaxV} x y z \\
\left(\mathrm{~mm} \mathrm{~h}^{-1}\right)\end{array}$ & $\begin{array}{l}\text { When } \\
\text { MaxVLOS }\end{array}$ & $\begin{array}{l}\text { When } \\
\text { MaxVxyz }\end{array}$ & Status \\
\hline A6 & -0.005 & -0.010 & -0.003 & -0.002 & 0.011 & 0.011 & 1.854 & 5.001 & 15 Mar 2015 19:00 & 15 Mar 2015 17:00 & \\
\hline A8 & -0.016 & -0.015 & 0.012 & -0.001 & 0.022 & 0.025 & 0.626 & 10.456 & 15 Mar 2015 20:00 & 2015 20:00 & \\
\hline B4 & -0.113 & 0.036 & -0.079 & 0.120 & 0.118 & 0.142 & 5.818 & 10.949 & 10 Mar 2015 14:00 & 15 Mar 2015 18:00 & Alarm \\
\hline S1 & -0.004 & -0.007 & -0.007 & -0.000 & 0.008 & 0.011 & & 4.389 & Mar 2015 19:00 & 15 Mar 2015 18:00 & \\
\hline $\mathrm{F} 2$ & -0.057 & 0.048 & -0.077 & 0.088 & 0.075 & 0.107 & 3.887 & 6.652 & 15 Mar 2015 23:00 & 15 Mar 2015 18:00 & Alarm \\
\hline $\mathrm{H} 3$ & -0.003 & -0.010 & -0.003 & -0.002 & 0.010 & 0.011 & 1.185 & 3.535 & 15 Mar 2015 16:00 & 15 Mar 2015 18:00 & \\
\hline $\mathrm{J} 3$ & 0.015 & 0.017 & -0.003 & -0.001 & 0.023 & 0.023 & 1.089 & 10.645 & 15 Mar 2015 20:00 & 15 Mar 2015 20:00 & \\
\hline B7 & -0.070 & 0.044 & -0.075 & 0.094 & 0.082 & 0.111 & 4.732 & 6.877 & 15 Mar 2015 16:00 & 15 Mar 2015 22:00 & Alarm \\
\hline L1 & -0.000 & -0.001 & 0.001 & -0.001 & 0.001 & 0.001 & 0.654 & 4.581 & 15 Mar 2015 19:00 & 16 Mar 2015 11:00 & \\
\hline G3 & -0.036 & 0.027 & -0.026 & 0.046 & 0.045 & 0.052 & 2.230 & 4.057 & 16 Mar 2015 12:00 & 16 Mar 2015 12:00 & Warning \\
\hline
\end{tabular}

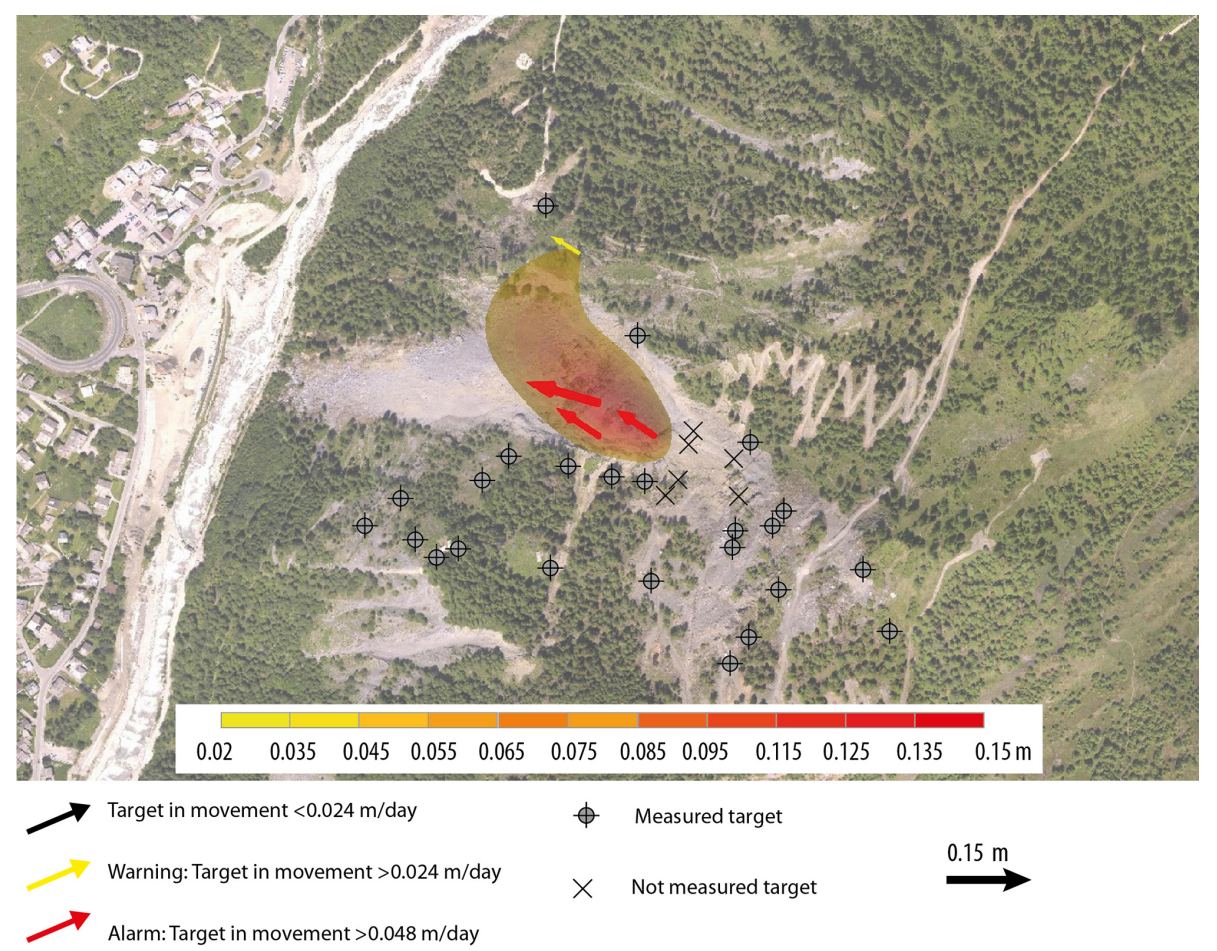

Figure 3. Example of rendering of the RTS data set dedicated to ROLE-1 related to a 24 h period between 15-16 March 2015. The RTS data set is published on a 3-D representation that evidence the most active landslide sector. This map is updated in near-real time by ADVICE.

\subsection{Periodic and/or on-demand updates}

To fully understand and interpret the landslide evolution, the availability of near-real time monitoring results is not sufficient. For this reason, the data management strategy consists also of periodic and/or on-demand reports (bulletins), which also take into account the definitions of actions and needs of the different LMT components. A first bulletin typology is mainly dedicated to ROLE-2 LMT members. This bulletin is issued quarterly, and considers all the data retrieved via the different monitoring instru- ments operating in the La Saxe area (at the moment of the publication the bulletins are available at the following link: http://www.regione.vda.it/territorio/commissariodelegato/ pianointerventi/attivitamonitoraggio_i.aspx). The main goals of the quarterly bulletin are: (i) to supply a complete description of the results obtained by the monitoring network in the considered time period; (ii) to identify and validate eventual trend changes with respect to the previous 3 months and to the same period in previous years; (iii) to audit the results, in order to suggest eventual updates and integrations to the current monitoring network. During specific emer- 


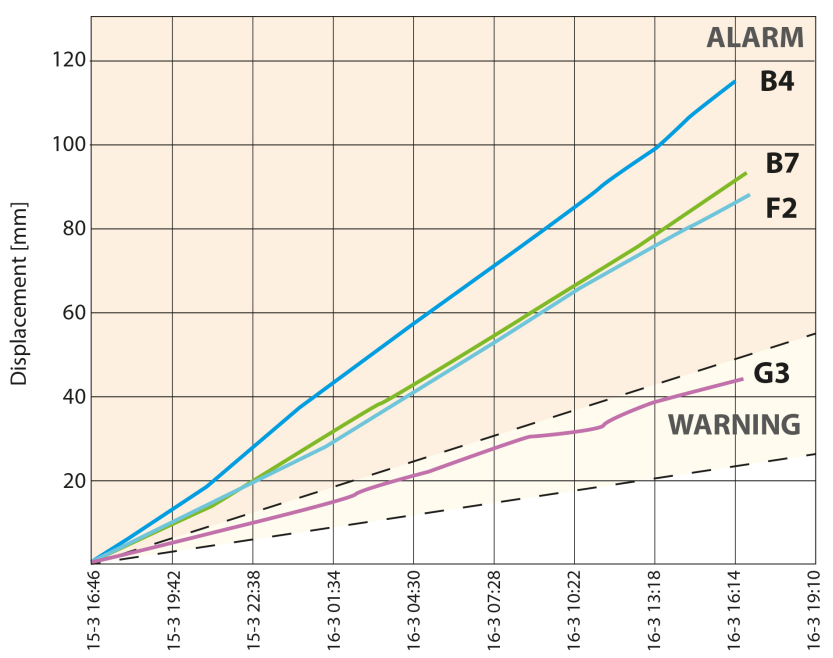

Figure 4. plot of the registered prims' displacement. The data set is the same in Fig. 3 but this representation is dedicated to ROLE-2. On the website, several plots related to different periods are published and updated in near-real time by ADVICE.

gency conditions, this kind of bulletin can be issued also over shorter time periods and eventually on demand.

In addition, a specific informative bulletin for population has been developed and tested. This bulletin is issued weekly during the most critical phase of the landslide evolution, and consists of a simplified visualization summarizing the displacement results obtained via the RTS in the previous 7-day period. Since the content, as well as the representation selected for this bulletin is intended for a straightforward presentation to a large amount of people, this bulletin can also be considered to inform the population about the landslide status (a copy of the bulletin is available in the Supplement).

\section{Discussion and conclusions}

The presentation of scientific data is a complex task, Garcia and Fearnley (2012) evidenced that often there is a real need to improve the relationship between the scientific community (and single researchers) and other stakeholders, in order to produce usable science. This is a critical issue, in particular during emergency conditions, when one of the main aspects commonly recognized is the knowledge gap between scientist and other involved stakeholders. This notion refers to making scientific research findings useful for societal or individual well-being and especially useful for decision makers. To accomplish this goal, scientists should make their research results accessible to the public, while using simple language that allows the general community to understand the information.

Our recent experiences in the management of emergency scenarios relevant to large slope instabilities, as well as other natural and anthropic hazards (Lollino et al., 2014; Man- coni et al., 2012, 2013b; Giordan et al., 2013), evidenced the need of integrated monitoring networks. However, the large amount of data retrieved may cause several problems if a proper approach for the sharing and correct communication of the results is missing. In this work, we describe the communication strategy applied to the La Saxe rockslide emergency scenario. Starting from the background and needs of the final receivers, we proposed and discussed a straightforward methodology aimed at sharing the landslide monitoring network results in an efficient manner. At the moment of writing, the entire La Saxe monitoring infrastructure and workflow from the acquisition to the presentation of the results is operational. By collecting all the data relevant to the La Saxe monitoring network in a unique webbased platform, comparative analysis of heterogeneous and complex information relevant to landslide displacements has been facilitated, in terms of time and effort. Following the results of this case-study, our aim is to define a standard approach to share the monitoring results, in order to disseminate the information about the recent evolution of the landslide, as well as the level of criticality, within all the people involved (scientists, technicians, civil protection operators, decision makers, politicians, press, population). To this end, near-real time results of the same data set have been represented according to the characteristic of the final users, to adapt the information to the final receivers. Moreover, the summaries in the quarterly bulletins describe and comment on the recent landslide evolution, identify critical areas and gaps in the monitoring network, and thus adapt instruments and eventually sampling policies along with the evolution of the landslide phenomenon. The application of dedicated products for the presentation of the monitoring results contribute to a proper understanding and evaluation of the landslide evolution. Decision makers can access, in near-real time, straightforward representations of the monitoring data, and can thus evaluate promptly the current situation. Moreover, simplified summaries revised by LMT experts (weekly bulletins) provide an efficient tool to discuss and interact with the population threatened by the landslide hazard. This allows for prompt countermeasures, which represent one of the key steps for the successful management of the most critical emergency phases. The presented experience and the results obtained on the Mont de La Saxe landslide showed how a dedicated communication strategy could help to correctly manage complex emergencies. In the recent years, this approach has been attempted in several monitoring contexts: (i) the Montaguto earthflow, southern Italy (Giordan et al., 2013); (ii) San Giovanni Profiamma, Foligno (PG), central Italy, where in April 2013 a landslide interrupted the important road that connects Rome to the Adriatic Sea through the central Apennines (SS3 Flaminia); (iii) monitoring activities related to the recovering of the Costa Concordia vessel wreck, near the coast of the Il Giglio Island (Manconi et al., 2013b). However, the Mont de La Saxe case study is an important and representative application for its peculiarities 


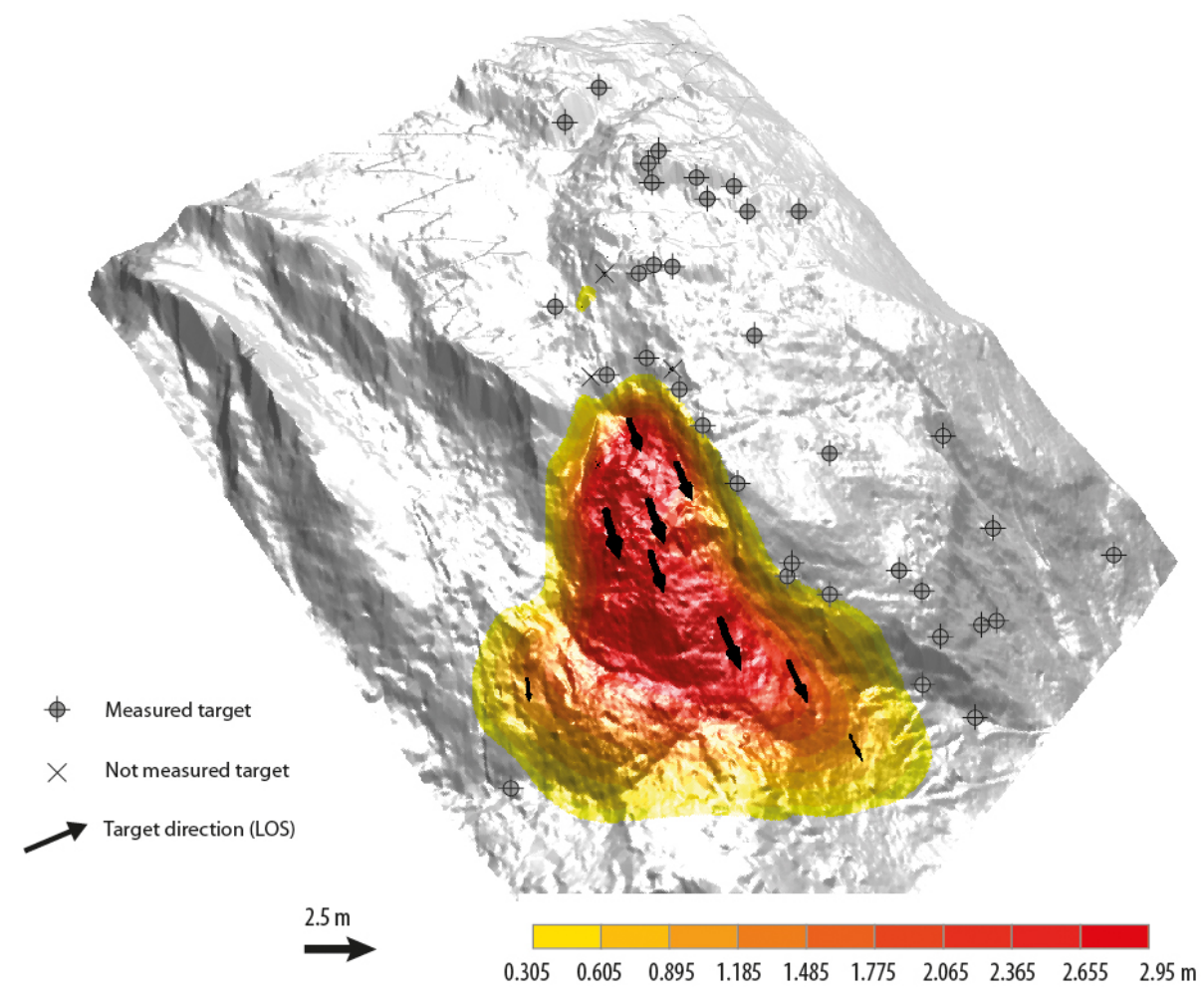

Figure 5. Map representing the displacement registered along the line of sight direction using the RTS and GB-SAR data. The LOS component measured by the different instruments is plotted in the same displacement map to have a more complete record of the ground displacements. This solution gives the possibility to have high resolution and compensate RTS measurements with 16 points derived from GB-SAR and located in the most inaccessible sectors where the installation of RTS target is not possible.

in terms of complexity of the phenomenon, highly exposed value and heterogeneity of the actors involved in the emergency. For this reason, this experience evidences that similar communication strategies have to be considered for the efficient management of monitoring activities relevant to landslide scenarios, as well as of other natural and/or anthropic hazards.

\section{The Supplement related to this article is available online at doi:10.5194/nhess-15-2009-2015-supplement.}

Acknowledgements. Suggestion as well as recommendation of two anonymous referees are gratefully acknowledged. We also would like to thank Dwayne Tannant for the accurate revision of the paper and for the important suggestions.

Edited by: P. Tarolli

Reviewed by: D. D. Tannant and two anonymous referees

\section{References}

Allasia, P., Manconi, A., Giordan, D., Baldo, M., and Lollino, G.: ADVICE: A New Approach for Near-Real-Time Monitoring of Surface Displacements in Landslide Hazard Scenarios, Sensors, 13, 8285-8302, doi:10.3390/s130708285, 2013.

Balis, B., Kasztelnik, M., Bubak, M., Bartynski, T., Gubała, T., Nowakowski, P., and Broekhuijsen, J.: The UrbanFlood Common Information Space for Early Warning Systems, Procedia Comput. Sci., 4, 96-105, doi:10.1016/j.procs.2011.04.011, 2011.

Blikra, L. H., KrIsTensen, L., and Lovisolo, M.: Subsurface monitoring of large rockslides in Norway: a key requirement for early warning, Ital. J. Eng. Geol. Environ., 6, 307-314, 2013.

Brückl, E., Brunner, F. K., Lang, E., Mertl, S., Müller, M., and Stary, U.: The Gradenbach Observatory - monitoring deepseated gravitational slope deformation by geodetic, hydrological, and seismological methods, Landslides, 10, 815-829, doi:10.1007/s10346-013-0417-1, 2013.

Crosta, G. B., di Prisco, C., Frattini, P., Frigerio, G., Castellanza, R., and Agliardi, F.: Chasing a complete understanding of the triggering mechanisms of a large rapidly evolving rockslide, Landslides, 11, 747-764, doi:10.1007/s10346-013-0433-1, 2014

Crosta, G. B., Lollino, G., Paolo, F., Giordan, D., Andrea, T., Carlo, R., and Davide, B.: Rockslide Monitoring Through Multitemporal LiDAR DEM and TLS Data Analysis, in: Engineering Geology for Society and Territory - Volume 2, edited by: Lollino, G., Giordan, D., Crosta, G. B., Corominas, J., Azzam, R., Wa- 
sowski, J., and Sciarra, N., 613-617, Springer International Publishing, Cham., available from: http://link.springer.com/10.1007/ 978-3-319-09057-3102, last access: 21 January 2015.

Di Biagio, E. and Kjekstad, O.: Early Warning, Instrumentation and Monitoring Landslides, 2nd Regional Training Course, RECLAIM II, 29 January-3 February 2007, Phuket, Thailand, 2007.

Garcia, C. and Fearnley, C. J.: Evaluating critical links in early warning systems for natural hazards, Environ. Hazards, 11, 123137, doi:10.1080/17477891.2011.609877, 2012.

Giordan, D., Allasia, P., Manconi, A., Baldo, M., Santangelo, M., Cardinali, M., Corazza, A., Albanese, V., Lollino, G., and Guzzetti, F.: Morphological and kinematic evolution of a large earthflow: The Montaguto landslide, southern Italy, Geomorphology, 187, 61-79, doi:10.1016/j.geomorph.2012.12.035, 2013.

Intrieri, E., Gigli, G., Mugnai, F., Fanti, R., and Casagli, N.: Design and implementation of a landslide early warning system, Eng. Geol., 147-148, 124-136, doi:10.1016/j.enggeo.2012.07.017, 2012.

Intrieri, E., Gigli, G., Casagli, N., and Nadim, F.: Brief communication "Landslide Early Warning System: toolbox and general concepts", Nat. Hazards Earth Syst. Sci., 13, 85-90, doi:10.5194/nhess-13-85-2013, 2013.

Leloup, P. H., Arnaud, N., Sobel, E. R., and Lacassin, R.: Alpine thermal and structural evolution of the highest external crystalline massif: the Mont Blanc, Tectonics, 24, TC4002, doi:10.1029/2004TC001676, 2005.

Lollino, P., Giordan, D., and Allasia, P.: The Montaguto earthflow: A back-analysis of the process of landslide propagation, Eng. Geol., 170, 66-79, doi:10.1016/j.enggeo.2013.12.011, 2014.

Lovisolo, M., Ghirotto, S., Scardia, G., and Battaglio, M.: The use of Differential Monitoring Stability (D.M.S.) for remote monitoring of excavation and landslide movements, Proceedings of the 6th International Symposium on Field Measurements in $\mathrm{Ge}-$ omechanics, Balkema, Oslo, 519-524, 2003.

Lu, P., Daehne, A., Travelletti, J., Casagli, N., Corsini, A., and Malet, J.-P.: Innovative Techniques for the Detection and Characterization of the Kinematics of Slow-Moving Landslides, in: Mountain Risks: From Prediction to Management and Governance, edited by: Asch, T. V., Corominas, J., Greiving, S., Malet, J.-P., and Sterlacchini, S., Springer, London, UK.,31-56, 2014.

Malet, J.-P., Maquaire, O., and Calais, E.: The use of Global Positioning System techniques for the continuous monitoring of landslides: application to the Super-Sauze earthflow (Alpes-deHaute-Provence, France), Geomorphology, 43, 33-54, 2002.

Manconi, A. and Giordan, D.: Landslide failure forecast in near-real-time, Geomat. Nat. Hazards Risk, 1-10, doi:10.1080/19475705.2014.942388, 2014.
Manconi, A. and Giordan, D.: Landslide early warning based on failure forecast models: the example of the Mt. de La Saxe rockslide, northern Italy, Nat. Hazards Earth Syst. Sci., 15, 16391644, doi:10.5194/nhess-15-1639-2015, 2015.

Manconi, A., Giordan, D., Allasia, P., Baldo, M., and Lollino, G.: Surface displacements following the Mw 6.3 L'Aquila earthquake: One year of continuous monitoring via Robotized Total Station, Ital. J. Geosci., 131, 403-409, 2012.

Manconi, A., Allasia, P., Giordan, D., Baldo, M., Lollino, G., Corazza, A., and Albanese, V.: Landslide 3D Surface Deformation Model Obtained Via RTS Measurements, in: Landslide Science and Practice, edited by: Margottini, C., Canuti, P., and Sassa, K., 431-436, Springer, Berlin, Heidelberg, available at: http://link.springer.com/chapter/10.1007/ 978-3-642-31445-256 (last access: 20 November 2013), 2013a.

Manconi, A., Allasia, P., Giordan, D., Baldo, M., Lollino, G.: Monitoring the stability of infrastructures in an emergency: The "Costa Concordia" vessel wreck. Wu F. \& Qi S. (eds). Global View of Engineering Geology and the Environment -Taylor \& Francis Group, London, 587-591. ISBN 978-1-138-00078-0, $2013 b$.

Michoud, C., Bazin, S., Blikra, L. H., Derron, M.-H., and Jaboyedoff, M.: Experiences from site-specific landslide early warning systems, Nat. Hazards Earth Syst. Sci., 13, 2659-2673, doi:10.5194/nhess-13-2659-2013, 2013.

Mileti, D. S. and Sorenson, J. H.: Communication of emergency public warnings: A social science perspective and state of-the-art assessment, Oak Ridge National Laboratory Rep. ORNL-6609, Oak Ridge National Laboratory, Washington, D.C., 145 pp., 1990.

Perello, P., Piana, F., and Martinotti, G.: Neo-Alpine structural features at the boundary between the Penninic and Helvetic domains (Prè S. Didier-Entrèves, Aosta valley, Italy), Eclogae Geol. Helv., 92, 347-359, 1999.

Tarchi, D., Casagli, N., Fanti, R., Leva, D. D., Luzi, G., Pasuto, A., Pieraccini, M., and Silvano, S.: Landslide monitoring by using ground-based SAR interferometry: an example of application to the Tessina landslide in Italy, Eng. Geol., 68, 15-30, doi:10.1016/S0013-7952(02)00196-5, 2003.

Wieczorek, G. F. and Snyder, J. B.: Monitoring slope movements, in: Geological Monitoring, edited by: Young, R. and Norby, L., Geological Society of America Boulder, Colorado, 245-271, 2009.

Xu, Q., Yuan, Y., Zeng, Y., and Hack, R.: Some new pre-warning criteria for creep slope failure, Sci. China Technol. Sci., 54, 210220, doi:10.1007/s11431-011-4640-5, 2011. 